\title{
Au-Ag Gradient Alloy Nanoparticles with Extended Surface Plasmon Resonance Wavelength: Synthesis via Microreaction
}

Li Sun ${ }^{1}$, Weiling Luan ${ }^{1 *}$, Shan-tung Tu ${ }^{1}$, Yue Jin Shan ${ }^{2}$

${ }^{1}$ The Key Laboratory of Safety Science of Pressurized System (MOE), School of Mechanical and Power Engineering, East China University of Science and Technology, Shanghai 200237, China.

${ }^{2}$ Department of Applied Chemistry, Faculty of Engineering, Utsunomiya University, 7-1-2 Yoto, Utsunomiya 321-8585, Japan.

* Corresponding author:luan@ecust.edu.cn (Weiling Luan), Tel/ Fax.: +8621 64253513

\section{Abstract}

$\mathrm{Au}-\mathrm{Ag}$ gradient alloy nanoparticles were directly synthesized in a microreaction system with their surface plasmon resonance been facilely adjusted. The surface plasmon resonance wavelength was red-shifted through increasing the raw ratio of $\mathrm{Au}^{3+}: \mathrm{Ag}^{+}$, decreasing the synthesis temperature or the residence time. A linear relationship was found between the surface plasmon resonance wavelength and the synthesis temperature, or the residence time. The range of surface plasmon resonance wavelength of monodispersed Au-Ag gradient alloy could be extended to 548 nm generated on the enrichment of $\mathrm{Au}$ as outer layer. It provided a suitable way to prepare Au-Ag gradient alloy NPs with longer surface plasmon resonance wavelength than $520 \mathrm{~nm}(\mathrm{Au})$ at low temperature.

Keywords: Au-Ag, gradient alloy, nanoparticles, surface plasmon resonance, microreaction system, wavelength shift

Citation: L. Sun, et al. Au-Ag Gradient Alloy Nanoparticles with Extended Surface Plasmon Resonance Wavelength: Synthesis via Microreaction. Nano Biomed. Eng.2011, 3(4), 232-235. DOI: 10.5101/nbe.v3i4.p232-235.

\section{Introduction}

Nowadays it is well known that materials at the nanoscale can display properties vastly different from the properties of the bulk and the constituent atoms or molecules [1]. Among all kinds of nanoparticles (NPs), $\mathrm{Au}, \mathrm{Ag}$ and bimetal Au-Ag NPs are of great interest because of their unique optical, electronic and catalytic properties. Especially, their enhanced surface plasmon resonance (SPR) of these materials is useful in many fields, including bioimaging, cancer therapy, drug delivery [2-4]. Generally, spherical Au and Ag NPs typically exhibit SPR wavelength around $520 \mathrm{~nm}$ and $410 \mathrm{~nm}$, respectively, while the wavelength of $\mathrm{Au}-\mathrm{Ag}$ alloy varied from $520 \mathrm{~nm}$ to $410 \mathrm{~nm}$ according to their composition [5]. By varying the shape of the NPs, SPR wavelength out of the above range can be obtained. For example, Ag$\mathrm{Au}$ with core-shell structure exhibits SPR wavelength as $560 \mathrm{~nm}$ [6]. However, the commonly adopted multisteps method for core-shell Au-Ag NPs is quite complex $[6,7]$, and the one-step method is difficult to provide monodispersed and small-sized NPs [8].

Comparing with core-shell structured NPs, the synthesis of Au-Ag alloy NPs is much simpler. Several methods including laser ablation, phase-transfer, digestive ripening, co-reduction of $\mathrm{Au}$ and $\mathrm{Ag}$ salts and galvanic replacement reaction have been conducted. Among them, the co-reduction of $\mathrm{Au}$ and $\mathrm{Ag}$ salts is regarded as the most suitable one to synthesize high-quality $\mathrm{Au}-\mathrm{Ag}$ NPs that have been applied in many fields [9, 10, 11]. Microreaction system is an excellent candidate to fulfill the co-reduction method due to its high control accuracy, superior size- and shape-selectivity, no inert atmosphere protection and fast heat and mass transfer [12].

In this paper, we studied the synthesis of Au-Ag gradient alloy NPs with an extended SPR wavelength via microreaction. The relationships between SPR wavelength, NPs structure and synthesis parameters were investigated. The properties were characterized by UVVis, EDS, and HR-TEM.

\section{Experimental section}

\subsection{Materials}

Oleylamine (OLA, Aladdin, AR), octadecene (ODE, Aladdin, AR), silver nitrate $\left(\mathrm{AgNO}_{3}\right.$, Aladdin, GR), 
chlorauric acid $\left(\mathrm{HAuC}_{14} \cdot 3 \mathrm{H}_{2} \mathrm{O}\right.$, Aladdin, $\left.\mathrm{AR}\right)$, ethanol (SCR, AR) and chloroform (SCR, AR) were used directly as raw materials without further treatment.

\subsection{Preparation of Au-Ag alloy nanoparticles}

Typically, $0.01 \mathrm{mmol}$ Silver nitrate and $0.01 \mathrm{mmol}$ Chlorauric acid were dissolved in $4 \mathrm{ml}$ OLA and 1 $\mathrm{ml}$ ODE, respectively, via ultrasonic stir at $60{ }^{\circ} \mathrm{C}$. The dissolved solutions were then mixed with magnetic stirrer. After that the mixture was sucked in the injector which was fixed on syringe pump, and then injected rapidly into the capillary when the temperature of oil bath got stable. The temperature was varied from $120{ }^{\circ} \mathrm{C}$ to $180{ }^{\circ} \mathrm{C}$ and the ratio of $\mathrm{Au}^{3+}: \mathrm{Ag}^{+}$in raw materials was adjusted from $1: 20$ to $5: 1$. The residence time was tuned by changing the flow rate supplied by a syringe pump.

\subsection{Characterization}

Energy-dispersive spectrum (EDS, INCA, Oxford) was applied to determine the $\mathrm{Au}$ mole fraction of various $\mathrm{Au}-\mathrm{Ag}$ alloy NPs. Ultraviolet visible spectrum (UV-Vis) analysis was carried out on a spectrophotometer (Cary 50, Varian). The relationship between SPR wavelength against the $\mathrm{Au}$ mole fraction of various $\mathrm{Au}-\mathrm{Ag}$ alloy NPs was investigated by UV-Vis absorption spectra and EDS. High resolution transmission electron microscope (HR-TEM, JEM-2100F, JEOL) operated at $200 \mathrm{kV}$ was used to observe the morphology. The sample for TEM was prepared by dipping an amorphous carbon-copper grid in a chloroform solution dispersed Au-Ag NPs homogeneously by sonicating for $5 \mathrm{~min}$, then the sample was left to evaporate in air at room temperature.

\section{Results and discussion}

\subsection{Influence of $\mathrm{Au}^{3+}: \mathrm{Ag}^{+}$raw ratio}

$\mathrm{Au}-\mathrm{Ag}$ alloy NPs have been synthesized by several methods, while their SPR wavelength was normally found between $520 \mathrm{~nm}$ and $410 \mathrm{~nm}$. In order to obtain longer SPR wavelength, the relationships between preparation conditions and the SPR wavelength were systematically studied.

Fig. 1 shows the relationship of the SPR wavelength and the ratio of $\mathrm{Au}^{3+}: \mathrm{Ag}^{+}$in raw materials. It is found that the SPR wavelength can be red-shifted from $470 \mathrm{~nm}$ to $532 \mathrm{~nm}$ by increasing the raw ratio of $\mathrm{Au}^{3+}: \mathrm{Ag}^{+}$from 1:20 to 5:1, which suggests a longer SPR wavelength can be obtained through changing the raw ratio. The SPR wavelength of $532 \mathrm{~nm}$ has exceeded the maximum of 520 $\mathrm{nm}$ given by Au-Ag alloy NPs. Besides, only one SPR wavelength exhibits in the spectra, illustrating as-obtained $\mathrm{Au}-\mathrm{Ag}$ NPs are of pure phase. The reason can be assigned to that a mixture of $\mathrm{Au}$ and Ag NPs will present two SPR peaks in their UV-Vis absorption spectra [5]. The inset of Fig. 1 illustrates the exponential relationship between SPR wavelength and the ratio of $\mathrm{Au}^{3+}: \mathrm{Ag}^{+}$.

EDS analysis was performed to examine the composition of the Au-Ag NPs. Fig. 2 reveals that $\mathrm{Au}$ and Ag element peaks appeared in the spectrum, implying other compositions such as $\mathrm{Cl}^{-}$precipitate are absent. Fig. 3 shows the plot of SPR wavelength against $\mathrm{Au}$ mole fraction of the final sample with raw ratios of $\mathrm{Au}^{3+}: \mathrm{Ag}^{+}$as $1: 5$ and 1:20. Here, the Au mole fraction was calculated from the EDS result, and different compositions were achieved by changing the residence time from 0 to $320 \mathrm{~s}$ with the same synthesis temperature as $180{ }^{\circ} \mathrm{C}$. A linear relationship is found when the raw ratio is $1: 20$. Because of the linear fashion and single absorption peak (shown in Fig. 1), as-obtained Au-Ag NPs were generally regarded as alloy with homogenous structure [13]. Besides, their SPR wavelength could be tuned from $410 \mathrm{~nm}$ to $520 \mathrm{~nm}$ depending on the composition. Comparably, when the raw ratio varied to $1: 5$, high $\mathrm{Au}$ mole fraction structured NPs exhibits inhomogeneous property. The SPR wavelength is red-shifted at same Au content with the increase of raw ratio from 1:20 to 1:5. For example, the SPR wavelength of $\mathrm{Au}_{0.4} \mathrm{Ag}_{0.6}$ is shifted from $455 \mathrm{~nm}$ to $489 \mathrm{~nm}$, and a similar trend is observed for Au0.6Ag0.4. This can be caused by the enrichment of $\mathrm{Au}$ in the outer layer of Au-Ag NPs. The composition of outer layer shows stronger effect on the SPR wavelength, comparing

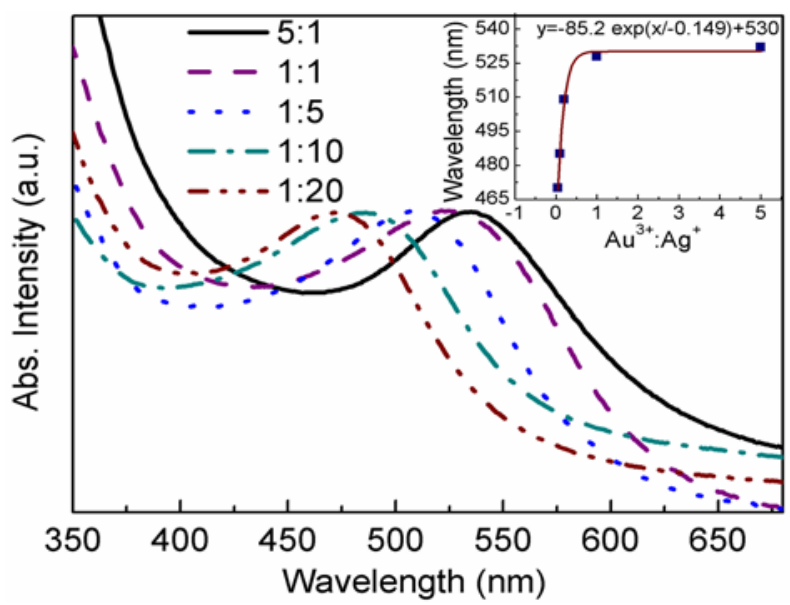

Fig. 1 Normalized UV-vis spectra of Au-Ag alloy NPs synthesized at $180{ }^{\circ} \mathrm{C}$ with raw ratio of $\mathrm{Au}^{3+}: \mathrm{Ag}^{+}$from $5: 1$ to $1: 20$ at $15 \mathrm{~s}$. Inset shows the change of SPR wavelength with the raw ratio.

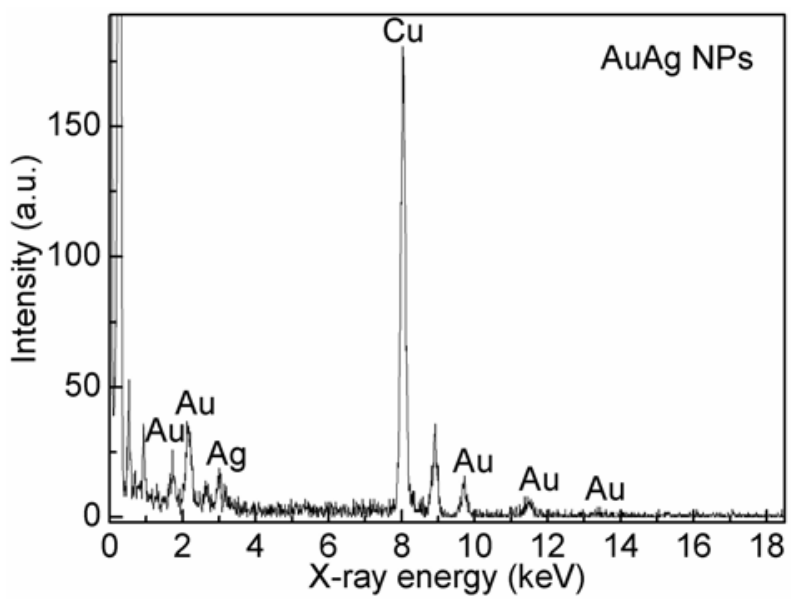

Fig. 2 EDS spectrum of Au-Ag NPs synthesized at $180{ }^{\circ} \mathrm{C}$. 


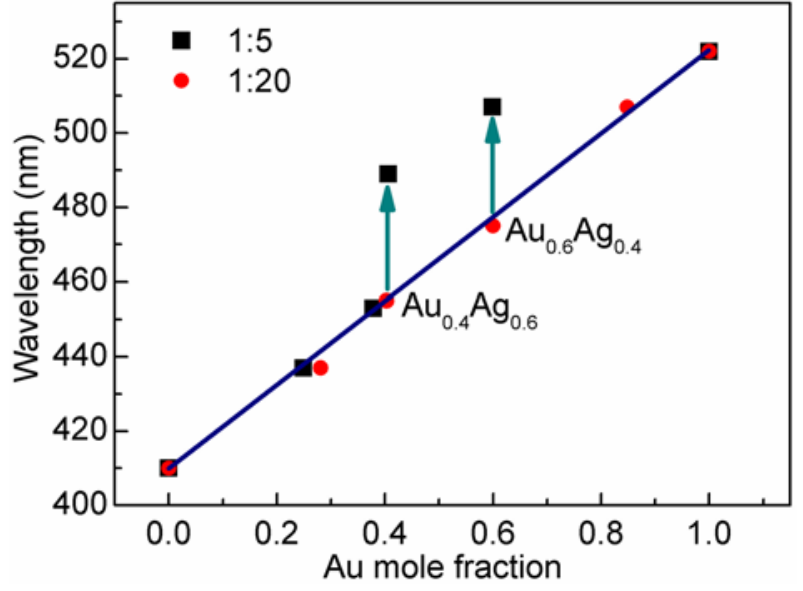

Fig. 3 Plot of the SPR wavelength against $\mathrm{Au}$ mole fraction of $\mathrm{Au}-\mathrm{Ag}$ NPs synthesized at $180^{\circ} \mathrm{C}$ with raw ratio of $\mathrm{Au}^{3+}: \mathrm{Ag}^{+}$as 1:5 and 1:20, respectively.

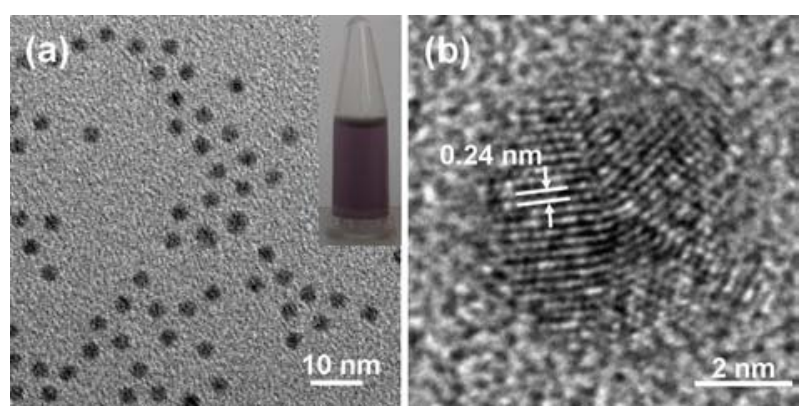

Fig. 4 (a) TEM image of Au-Ag alloy NPs (540 nm) synthesized at 180 ${ }^{\circ} \mathrm{C}$ with raw ratio of $\mathrm{Au}^{3+}: \mathrm{Ag}^{+}$as 5:1. (b) HR-TEM image of (a). Insert of (a) is the photograph under door light.

with the inside part. The SPR wavelength of $\mathrm{Au}(520 \mathrm{~nm})$ is bigger than $\mathrm{Ag}(410 \mathrm{~nm})$, which generates longer SPR wavelength when the surface is Au-rich.

To further observe the size and micro-structure of AuAg NPs, TEM and HR-TEM images were conducted and shown in Fig.4. Au-Ag NPs display mono-dispersion with average size as less than $5 \mathrm{~nm}$. As shown in the inset of Fig. 4a, the color of Au-Ag NPs with the SPR wavelength of $540 \mathrm{~nm}$ is dark purple, which is similar as that of reported Ag-Au core-shell NPs [8]. However, the HRTEM image in Fig. 4b shows a twinned structure instead of core-shell one. The interplanar distance measured from the adjacent lattice fringes is $0.24 \mathrm{~nm}$, corresponding to (111) planes of the face-centered cubic (fcc) Au or Ag. The Ag-Au core-shell NPs were usually prepared under $100{ }^{\circ} \mathrm{C}$ to avoid the diffusion of $\mathrm{Au}$ and $\mathrm{Ag}$ because the diffusion got stronger after then based on Arrhenius equipment [7]. Therefore, as-synthesized Au-Ag NPs can be proved as gradient alloy structure rather than core-shell structure.

\subsection{Influence of reaction temperature}

The reaction temperature intensively affects the nucleation rate of $\mathrm{Au}$ and $\mathrm{Ag}$ ions. Structures reflected by the SPR wavelength are influenced by the relative nucleation rate in one-step process. Fig. 5 shows almost a

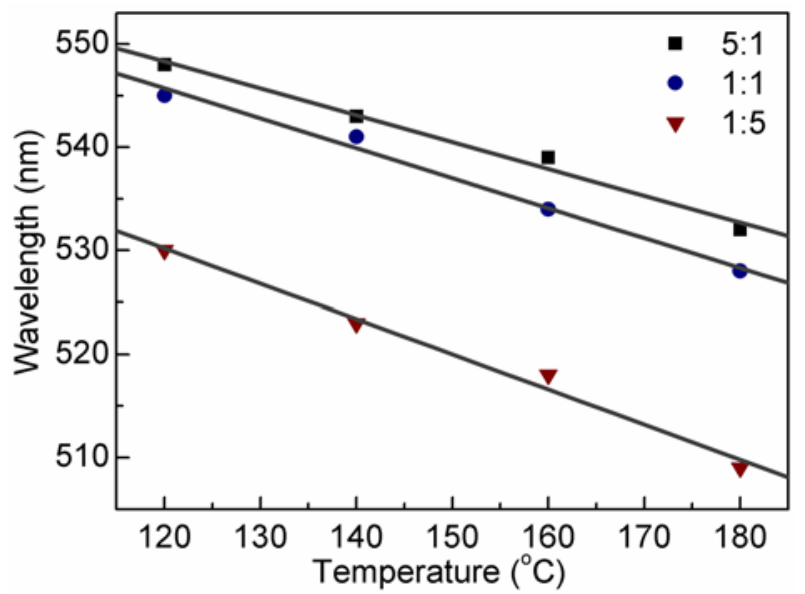

Fig. 5 The SPR wavelength dependence of the reaction temperature from $120^{\circ} \mathrm{C}$ to $180^{\circ} \mathrm{C}$.

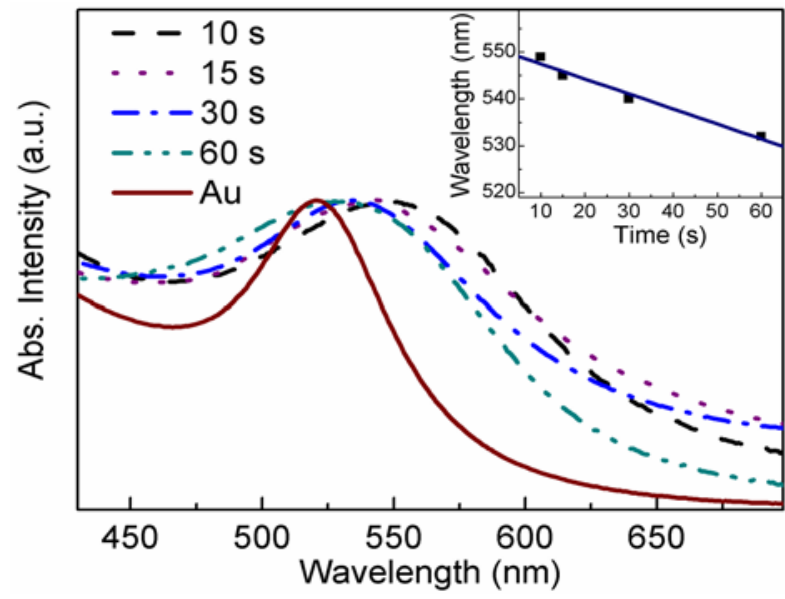

Fig. 6 Normalized UV-vis spectra of Au-Ag alloy NPs synthesized at $120{ }^{\circ} \mathrm{C}$ in raw ratio of $\mathrm{Au}^{3+}: \mathrm{Ag}^{+}$as $1: 1$. Inset exhibits the relationship between the SPR wavelength and the residence time.

linear relationship between the reaction temperature and the SPR wavelength of Au-Ag alloy NPs with raw ratio of $\mathrm{Au}^{3+}: \mathrm{Ag}^{+}$as 5:1, 1:1, and 1:5, respectively. The SPR wavelength can be red-shifted through the decreasing of the reaction temperature. The longest SPR wavelength of $548 \mathrm{~nm}$ is obtained at $120{ }^{\circ} \mathrm{C}$ with raw ratio of $5: 1$. The lower reduction temperature resulted in a higher relative nucleation rate of $\mathrm{Au}$ ions, which caused a strong $\mathrm{Au}$ ions nucleation in a short time. Thus, the diffusion between $\mathrm{Au}$ and Ag became insufficient, and then induced the gradient structure of alloy. The diffusion rate could be enhanced by the temperature. As a result, the SPR wavelength was shortened at higher reaction temperature. Au-Ag gradient alloy NPs with a long SPR wavelength could be facilely obtained via low temperature.

\subsection{Influence of residence time}

The residence time also shows great effect on the SPR wavelength. As displayed in Fig. 6, the SPR wavelength blue-shifted with the increase of the residence time. When the residence time is $60 \mathrm{~s}$, the SPR wavelength is similar as that of Au NPs as $520 \mathrm{~nm}$. This phenomenon was mainly due to the change of the relative nucleation 
rate and the diffusion of $\mathrm{Au}$ and $\mathrm{Ag}$. The $\mathrm{Au}$ precursor was consumed largely in a short time, which made the concentration of ions lower and further reduced the nucleation rate. However, the Ag precursor just showed a low consumption because of its relative slow reduction rate, which kept the nucleation of $\mathrm{Ag}$ as a constant. Thus, the decline of the relative nucleation of Au led to the blueshift of the SPR wavelength. Meantime, the continuous diffusion between $\mathrm{Au}$ and $\mathrm{Ag}$ with the residence time could also make the SPR wavelength blue-shift. The inset of Fig. 6 illustrates a linear relationship between the SPR wavelength and the residence time, suggesting the SPR wavelength from $549 \mathrm{~nm}$ to $532 \mathrm{~nm}$ can be linearly tuned.

\section{Conclusions}

$\mathrm{Au}-\mathrm{Ag}$ gradient alloy NPs were synthesized in a microreaction system. A SPR peak of $548 \mathrm{~nm}$ was obtained at $120{ }^{\circ} \mathrm{C}$ with a raw ratio of $\mathrm{Au}^{3+}: \mathrm{Ag}^{+}$as $5: 1$. The SPR wavelength was red-shifted by separately decreasing the synthesis temperature, shortening the residence time or enhancing the ratio of $\mathrm{Au}^{3+}: \mathrm{Ag}^{+}$. An exponential relationship was presented between SPR wavelength and the ratio of $\mathrm{Au}^{3+}: \mathrm{Ag}^{+}$at $180{ }^{\circ} \mathrm{C}$ with the residence time of $15 \mathrm{~s}$. Either the synthesis temperature or the residence time exhibited almost a linear relationship with the SPR wavelength at the reported parameter.

\section{Acknowledgements}

Authors appreciated the financial supports from the Fundamental Research Funds for National Nature Science Foundation of China (51172072), the Central Universities (WJ0913001), the Focus of Scientific and Technological Research Projects (109063), and the State Key Laboratory of Chemical Engineering at ECUST (SKL-ChE-08C09).

\section{References}

1. Burda C, Chen XB, Narayanan R, EI-Sayed MA. Chemistry and Properties of Nanocrystals of Different Shapes. Chem. Rev. 2005; 105: 1025-1102. doi: 10.1021/cr030063a

2. (a) Bardhan R, Grady NK, Cole JR, Joshi A, Halas NJ. Fluorescence Enhancement by Au Nanostructures: Nanoshells and Nanorods. ACS Nano 2009; 3: 744-752. doi: 10.1021/nn900001q. (b) Quarta A, Di Corato R, Manna L, Argentiere S, Cingolani R, Barbarella G, Pellegrino T. Multifunctional Nanostructures Based on Inorganic Nanoparticles and Oligothiophenes and Their Exploitation for Cellular Studies. J. Am. Chem. Soc. 2008; 130: 10545-10555. doi: 10.1021/ja800102v

3. (a) Huang XH, EI-Sayed IH, Qian W, EI-Sayed MA. Cancer Cell Imaging and Photothermal Therapy in the Near-Infrared Region by Using Gold Nanorods. J. Am. Chem. Soc. 2006; 128: 2115-2120. doi 10.1021/ja057254a. (b) Nann T. Nanoparticles in photodynamic therapy. Nano Biomed. Eng. 2011; 3: 137-143. doi: 10.5101/nbe.v3i2. p137-143.

4. (a) Liong M, Lu J, Kovochich M, Xia T, Ruehm SG, Nel AE, Tamanoi F, Zink JI. Multifunctional Inorganic Nanoparticles for Imaging, Targeting, and Drug Delivery. ACS Nano 2006; 2: 889-896. doi: 10.1021/nn800072t. (b) Cui DX, Zhang H, Wang K, Gao F, Zhang, XQ, Asahi T, He R, Osaka, T. Gold nanoparticles enhance efficiency of in vitro gene transcription-translation system. Nano Biomed. Eng. 2011; 3: 120-125. doi: 10.5101/nbe.v3i2.p120-125.

5. Devarajan S, Bera P, Sampath S. Bimetallic nanoparticles: A single step synthesis, stabilization, and characterization of $\mathrm{Au}-\mathrm{Ag}, \mathrm{Au}-\mathrm{Pd}$, and $\mathrm{Au}-\mathrm{Pt}$ in sol-gel derived silicates. J. Colloid Interf. Sci. 2005; 290: 117-129. doi: 10.1016/j.jcis.2005.04.034.

6. (a) Yang J, Lee JY, Too H-P. Core-Shell Ag-Au Nanoparticles from Replacement Reaction in Organic Medium. J. Phys. Chem. B 2005; 109: 19208-19212. doi: 10.1021/jp052242x. (b) Chen DP, Zhu G, Zhu XG, Qiao XL, Chen JG. Effects of silver nanowires on the electrochemical performance of LiFePO4. Nano Biomed. Eng. 2011; 3: 19-24. doi: 10.5101/nbe.v3i1.p19-24

7. Wang C, Peng S, Chan R, Sun SH. Synthesis of AuAg Alloy Nanoparticles from Core/Shell-Structured Ag/Au. Small 2009; 5: 567-570. doi: 10.1002/smll.200801169.

8. (a) Uppal MA, Ewing MB, Parkin IP. One-Pot Synthesis of CoreShell Silver-Gold Nanoparticle Solutions and Their Interaction with Methylene Blue Dye. Eur. J. Inorg. Chem. 2011; 4534-4544. doi: 10.1002/ejic.201100536. (b) Chen SH, Ji YX, Lian Q, Wen YL, Shen HB, Jia, NQ. Gold nanorods coated with multilayer polyelectrolyte as intracellular delivery vector of antisense oligonucleotides. Nano Biomed. Eng. 2010; 2: 15-23. doi: 10.5101/nbe.v2i1.p15-23.

9. Wang A-Q, Liu J-H, Lin T-S, Mou C-Y. A novel efficient Au-Ag alloy catalyst system: preparation, activity, and characterization. J. Cata. 2005; 233: 186-197. doi: 10.1016/j.jcat.2005.04.028.

10.(a) Mallin MP, Murphy C. Solution-phase synthesis of sub-10 nm Au-Ag alloy nanoparticles. Nano Lett. 2002; 2: 1235-1237. doi: 10.10 21/n1025774n. (b) Zhang YG. Relations between size and function of natural substance particles. Nano Biomed. Eng. 2011; 3: 1-16. doi: 10.5101/nbe.v3i1.p1-16.

11.Wang C, Yin HF, Chan R, Peng S, Dai S, Sun SH. One-pot synthesis of oleylamine coated AuAg alloy NPs and their catalysis for $\mathrm{CO}$ oxidation. Chem Mater 2009, 21: 433-435. doi: 10.1021/cm802753j.

12.(a) Nightingale MA, Mello JC. Microscale synthesis of quantum dots. J. Mater. Chem. 2010; 20: 8454-8463. doi: 10.1039/c0jm01221a. (b) Luan WL, Yang HW, Tu S-T. Synthesis of efficiently green luminescent $\mathrm{CdSe} / \mathrm{ZnS}$ nanocrystals via microfluidic reaction. Nanoscale Res. Lett. 2008; 3: 134-139. doi: 10.1007/s11671-0089125-5. (c) Tu S-T, Yu XH, Luan WL, Loewe H. Development of micro chemical, biological and thermal systems in China: A review. Chem. Eng. J. 2010; 163: 165-179. doi: 10.1016/j.cej.2010.07.021.

13.Poovathinthodiyi R, Jie F, Scoot LW. A simple and green method for the synthesis of $\mathrm{Au}, \mathrm{Ag}$, and $\mathrm{Au}-\mathrm{Ag}$ alloy nanoparticles. Green Chem. 2006; 8: 34-38. doi: 10.1039/b512540e.

Copyright:(c) 2011 L. Sun, et al. This is an open-access article distributed under the terms of the Creative Commons Attribution License, which permits unrestricted use, distribution, and reproduction in any medium, provided the original author and source are credited. 